\title{
Malignant granular cell tumour: a case report and re-evaluation of adverse prognostic features
}

\author{
Renu Mariam Thomas \\ Medical Trust Hospital, Kochi, Kerala, India \\ Correspondence: Renu Mariam Thomas, Consultant Pathologist. Address: Department of Pathology, Lakeshore Hospital \\ and Research Centre, Kochi, India. E-mail: resurenu@yahoo.co.uk
}

Received: March 4, 2014

Accepted: June 13, 2014

Online Published: June 20, 2014

DOI : $10.5430 /$ crcp.v1n2p135

URL: http://dx.doi.org/10.5430/crcp.v1n2p135

\begin{abstract}
Granular cell tumours (GCT) mostly follow a benign course. The malignant cases account for $1 \%-2 \%$ of all GCTs with most cases reported in African-American females. It is found in soft tissue of the thigh, rather than the head and neck area for benign lesions. In 1998, Fanburg-Smith et al. proposed six histologic criteria for selection of benign, atypical and malignant cases in the study of 73 GCT cases. However, the reproducibility of some of their criteria is questionable and malignant granular cell tumour still remains a grey zone and lack clear diagnostic criteria. We hereby report a granular cell tumour in an elderly female which morphologically did not fulfill criteria of malignant GCT by Fanburg-Smith et al. but behaved in an aggressive fashion with repeated recurrences and metastases. The need for a simple and practical diagnostic approach is emphasized.
\end{abstract}

\section{Key words}

Malignant granular cell tumour, Malignancy, Prognostic features

\section{I ntroduction}

Granular cell tumor (GCT) is an interesting tumor, with most cases following a benign course, commonly occurs in superficial locations of middle aged patients and usually measures less than $3 \mathrm{~cm}$. in diameter. A wide range of other locations including viscera are recorded; however origin within skeletal muscle is infrequent ${ }^{[1]}$. We encountered a deep seated GCT in the left thigh of an elderly female which morphologically did not show any conventional features of malignancy but it behaved in an aggressive fashion. The aim of this case report was to increase awareness of the existence of a rare malignant variant of GCT with metastatic potential.

\section{Case report}

A 68 year old female presented with a firm to hard swelling on the left thigh. It's noticed for six weeks. Fine needle aspiration cytology (FNAC) from the mass showed the features of granular cell tumor. Magnetic resonance imaging (MRI) scan of the left thigh showed a well encapsulated oblong lesion involving the left adductor magnus muscle with expansion and pressure effect on the adjacent muscles, appearances consistent with a soft tissue neoplasm. Excision of the entire length of the involved muscle and overlying deep fascia was done. The excised mass measured $14.5 \mathrm{~cm} \times 8 \mathrm{~cm} \times 5$ 
$\mathrm{cm}$ which consisted of muscle, fat and tendon. On sectioning, there was a pale yellow tumor with irregular margins measuring $8.5 \mathrm{~cm} \times 7 \mathrm{~cm} \times 4.5 \mathrm{~cm}$. On histological examination, it showed a circumscribed neoplasm within the skeletal muscle and composed of nests of uniform polygonal cells with abundant eosinophilic granular cytoplasm, round nuclei and occasional visible nucleoli (see Figure 1). Focal spindling and fasciculation was present (see Figure 2). Up to 3 mitoses / 10 high power field (at 400× magnification) were identified. No significant pleomorphism was present and there was no necrosis. However, the tumor was seen extending up to the resection margins. A diagnosis of GCT was made and the patient was advised close follow up in view of inadequate clearance. Another MRI scan taken five months later as a follow up action revealed residual lesion in left thigh with signal intensity. A year later, a mass was noticed in the left femoral triangle from which an FNAC was done and the FNAC result suggested metastatic GCT in lymph nodes. The mass was excised with left groin dissection. The histopathology report indicated recurrence of GCT showing similar morphological features to the original tumor with metastatic deposits in left inguinal and femoral lymph nodes. This was followed by a series of metastases which included metastatic deposits on left chest wall and on skin over left flank, both were excised. Two years later, bilateral lung metastases were noted on computed tomography (CT) thorax which was confirmed on CT guided FNAC. A few months later, she developed metastatic deposits in left paraspinal muscle and in left parasternal muscle. They were excised. CT imaging of thorax and abdomen revealed multiple lung and abdominal metastases with enlarged left external iliac and inguinal lymph nodes. They were confirmed on CT guided FNAC. She was started on chemotherapy. Inspite of completing six cycles of ifosfamide and epirubicin, she expired, six years after her initial presentation.

Figure 1. Granular cell tumour with abundant granular eosinophilic cytoplasm, round nuclei and occasional visible nucleoli. H\&E; original magnification. $\times 40$

Figure 2. Granular cell tumour showing focal spindling and fasciculation. H\&E; original magnification. $\times 20$
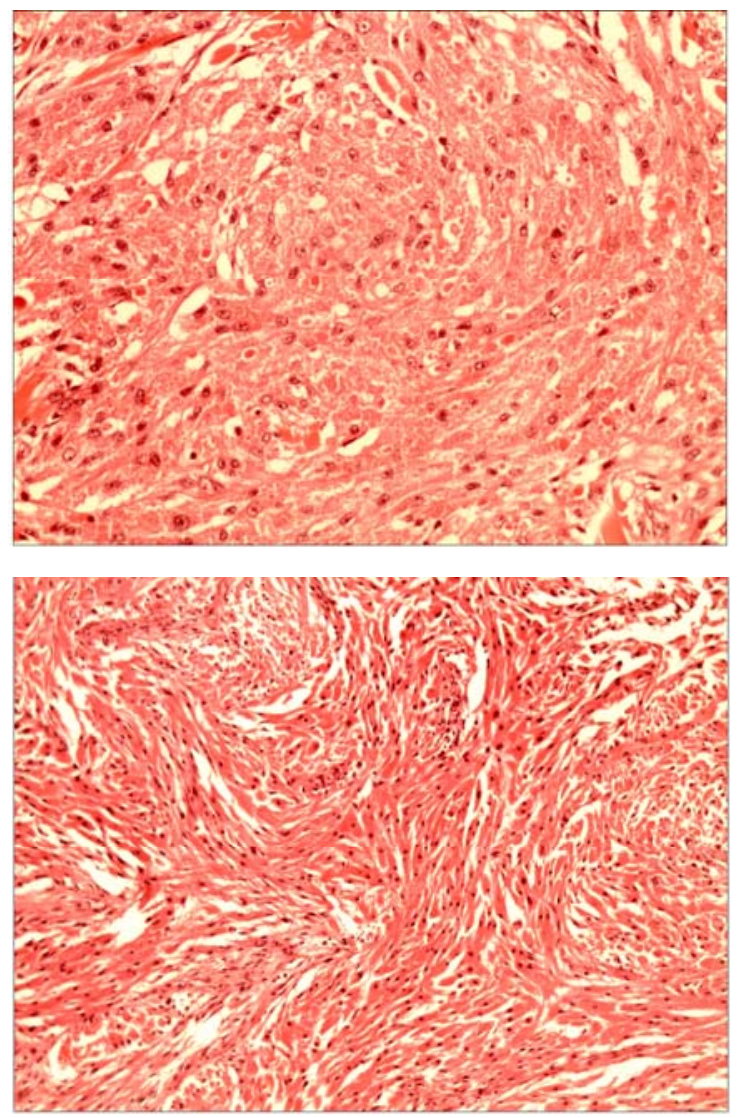

\section{Discussion}

The histological criteria of malignant granular cell tumour was established in 1998 by Fanburg-Smith et al. ${ }^{[2]}$ and they include necrosis, spindling, vesicular nuclei with large nucleoli, increased mitotic activity ( $>2$ mitoses/10HPF at 200× magnification), high nuclear to cytoplasmic ratio and pleomorphism with additional features like local recurrence, 
metastasis, large tumor size, older patient age and Ki 67 values greater than $10 \%$ being regarded as statistically significant adverse prognostic factors. However, these criteria may not hold value in individual cases and histological diagnosis of malignancy can be challenging in these tumors as in the present case which closely resembled its benign counterpart except for focal spindling and a marginally increased mitotic rate. Several authors have expressed the difficulty in diagnosing malignancy in granular cell tumors based on morphology alone. Tsuchida et al. in their article ${ }^{[3]}$ emphasize large size and intramuscular location along with atypical mitoses as pertinent findings in making the diagnosis of malignancy in GCT. In a clinico pathologic analysis of 10 cases of malignant GCT by Wang et al. ${ }^{[4]}$, nine cases after careful assessment showed at least three suspicious histological features, the remaining case demonstrated benign appearing features but behaved in a malignant fashion. The authors recommend a modified criterion of mitotic count $\left(>5 / 50 \mathrm{HPF}\right.$ instead of $>2 / 10 \mathrm{HPF}$ ). Nasser et al. ${ }^{[5]}$ in their attempt to simplify the selection criteria, propose an algorithmic approach based only on necrosis and mitoses, the two popular histological criteria in the classification of most malignant tumors. In all these reports, malignant tumors show a statistically significant larger size. Although it is difficult to draw conclusions from a single case and limited available literature, it is the author's view that large and deep seated GCT should be considered as distinct entities with uncertain malignant potential, regardless of the histological features. Further studies with large number of cases are needed to verify this. A clinico pathological classification into low risk and high risk groups as designed for gastrointestinal stromal tumors, in co-operating features like location, size and mitotic count may be helpful in better understanding the biological behavior of these tumors. Until such studies emerge with clear criteria, all attempts should be taken to detect any occult metastases ${ }^{[6]}$ when GCTs are large or when deeply located and wide local excision with regional lymph node dissection should be considered that may improve the long term outcome. No specific cytogenetic alterations are detected in these tumors so far, that can aid in diagnosis or therapy ${ }^{[7]}$. Chemotherapy and radiotherapy have not been shown to improve the clinical course of the disease.

\section{Conflict of interests}

The author does not have any conflict of interests.

\section{References}

[1] Fletcher CDM. Diagnostic Histopathology of Tumours, 4th ed. Philadelphia: Elsevier limited. 2013; 2045.

[2] Fanburg-Smith JC, Meis-Kindblom JM, Fante R, Kindblom LG. Malignant granular cell tumor of soft tissue: diagnostic criteria and clinico pathologic correlation. Am J Surg Pathol. 1998; 22: 779-94. PMid: 9669341. http://dx.doi.org/10.1097/00000478-199807000-00001

[3] Tsuchida T, Okada K, Itoi E, Sato T, Sato K. Intramuscular malignant granular cell tumor. Skeletal Radiol. $1997 ; 26: 116-21$. PMid: 9060104. http://dx.doi.org/10.1007/s002560050204

[4] Wang J, Zhu XZ, Zhang RY. Malignant granular cell tumor: a clinicopathologic analysis of 10 cases with review of literature. Zhonghua Bing Li Xue Za Zhi. 2004; 33: 497-502. PMid: 15634442.

[5] Nassera H, Ahmed Y, Szpunan SM, Kowalskia PJ. Malignant granular cell tumor: A look into the diagnostic criteria. Pathology Research and Practice. 2011; 207: 164-168. PMid: 21282016. http://dx.doi.org/10.1016/j.prp.2010.12.007

[6] Jardines L, Cheung L, Livolsi V, Hendrickson S, Brooks JJ. Malignant granular cell tumors: report of a case and review of the literature. Surgery. 1994; 116: 49-54. PMid: 8023268

[7] Nasser H, Danforth RD Jr, Sunbuli M, Dimitrijevie O. Malignant granular cell tumor: case report with a novel karyotype and review of the literature. Ann Diagn Pathol. 2010; 14: 273-8. PMid: 20637434.

http://dx.doi.org/10.1016/j.anndiagpath.2009.08.004 